\title{
Modeling of aircraft jet noise in airports
}

\author{
Hristina Georgieva ${ }^{1 *}$, Krasin Georgiev ${ }^{2}$ \\ ${ }^{1}$ Technical University - Sofia, Mechanical Department, 1756 Sofia, 8 Kliment Ohridski Blvd., Bulgaria \\ ${ }^{2}$ Technical University - Sofia, Aeronautical Department, 1756 Sofia, 8 Kliment Ohridski Blvd., Bulgaria
}

\begin{abstract}
A mathematical model with 4 degree of freedom created in Matlab for aircraft final landing trajectory is described in this paper. A midsize commercial passenger aircraft similar to an Airbus A320 has been chosen as a reference aircraft. The parameters of model are obtained from Airbus, Eurocontrol and the approach procedure at the Munich airport is selected up from Jeppesen Airway manual. A semi-empirical model of Stone for predicting the jet noise has been used. The proposed model was validated against 10 real flights obtained from Aircraft noise monitoring at Munich airport. The computed error between the real data and modelling is reported on. Obtained results are presented numerical and graphically. The observed effects of aircraft speed, aircraft angle of descent and aircraft weight for reduction of aircraft jet noise in airports represent subjects of discussions in the paper.
\end{abstract}

\section{Introduction}

Contemporary society is difficult to imagine without the air transport and related improvements, facilitating everyday life. It causes noise pollution of the environment, which is considered today to be one of the most significant environmental problem affecting population and the environment. The aircraft noise is highest on the airports and communities around airports. It can lead to community annoyance, sleep disturbance and could increase the risk of high blood pressure, heart disease, heart attack for people living near airports. Significant research is currently being undertaken with the goal of reducing aircraft noise [1]. The Environmental Noise Directive (END) [2] is the legislative instrument at European Union (EU) under that environmental noise is monitored and necessary actions (standards and recommended) norms are taken. To reduce the noise levels in airports and place close to the airports the Directive applies noise criteria for noise mapping, developing and implanting action plants. The theoretical models allow predicting and managing the real object. There are two types of models. The theoretical models of the first group are based on empirical data and use specialized software products $[3,4]$. This work is focused on the second type of models that use the basic principles of aircraft modelling. They represent the aircraft as a point-mass model including the aerodynamics of the aircraft itself. The differential equations describe the aircraft position in space and allow finding an appropriate relationship between the investigated parameters. They allow the optimization of aircraft trajectories and determination also of noise level from these trajectories. The models that are used in the literature are with 4 to 6 degrees of freedom $[5,6,7]$. Khardi and Abdallah propose a 4-degree model of aircraft [5] simulating the final trajectory of landing. In their work they use two approaches for minimization of aircraft jet noise. The first one suggests a constant throttle setting and variation of angle descent between $0^{\circ}$ and $-4.5^{\circ}$. The second one defines two stages of throttle section which variation is between 0 and 0.6 and the angle of descent also varies between $0^{\circ}$ and $-4.5^{\circ}$. Menendez describes an aircraft model [6] with 6 degrees of freedom for evaluation of aircraft noise abatement procedures. He is focused on the more flexible trajectories which will enable the definition of optimal flight procedures regarding the noise annoyance impact, especially in the arrival and departure phases of flights. In work [7] the noise reduction is obtained as coupling the aircraft nose. The two similar commercial aircraft are supposed to land successively on one runway without conflict. The aircraft movement of the two aircrafts is presented by mathematical model with 6 degrees of freedom. While maintaining an evolution of the flight approach procedures the same optimal trajectory has been achieved for the two-aircraft even though the procedures are different. Koenig et al. [8] describe the increase of the aircraft angle of descent to reduce the noise level without necessity of flight procedure change. In the above models the semi-empirical model of Stone [9] is used to predict the engine jet noise level for single and mixed dual jets up to bypass ratios of 15 as the main source. In general, the model can be applied to subsonic or supersonic flights up to Mach numbers of 2.5. J. E. Bridges et al. [10] analyse the method and prove its applicability to modern engines with a high bypass ratio.

The main sources of aircraft noise are the engine and its body. In the current work a mathematical model with 4 degree of freedom created in Matlab is described. It includes two sections. The first presents the modelling of aircraft final landing trajectory and the second one the modelling of engine jet noise level. The model permits to

\footnotetext{
* Corresponding author: hgeorgieva@tu-sofia.bg
} 
investigate different variants of aircraft landing trajectories for reducing the aircraft jet noise level in airports through the variation of angle of descent, velocity of descent and aircraft weight. Hence it has been proposed a complete method for reducing the aircraft jet engine noise, including all the possible components on which it depends.

\section{Methodology of data selection}

\subsection{For modelling of aircraft landing trajectory}

The aircraft chosen for the simulation is similar to the Airbus A320 which is widely used for short to medium range flights [11]. According to performance training manual of Airbus [12] the aircraft velocity of descent varies from 82 to $118 \mathrm{~m} / \mathrm{s}$. Data for modelling of aircraft landing trajectory on Munich airport (Fig. 1) is taken from the Jeppesen Airway manual [13].

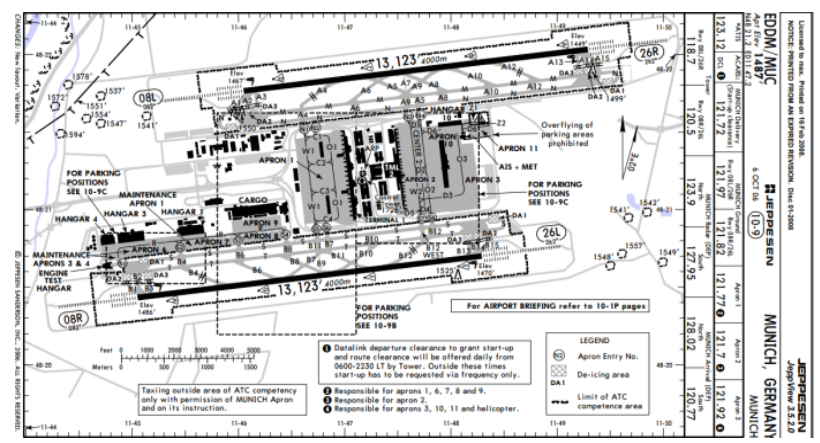

Fig. 1. Runway map of Munich airport.

In Table 1 is shown the selected parameters: the runway altitude, altitude of descent and the angle of descent. This aircraft is equipped by two types of engines: CFM565A and V2527A. According the data from Eurocontrol [14] widely used is CFM565A engine. This engine develops a maximum thrust force of $118 \mathrm{kN}$ (Table 1).

Table 1. Aircraft landing trajectory modelling data.

\begin{tabular}{|c|l|c|c|}
\hline Data from & \multicolumn{1}{|c|}{ Parameter } & Value & Unit \\
\hline \multirow{5}{*}{ Aircraft } & Max landing weight, $m_{M T L} W$ & 64500 & $\mathrm{~kg}$ \\
\cline { 2 - 4 } & Wing span, $b$ & 35.8 & $\mathrm{~m}$ \\
\cline { 2 - 4 } & Wing are, $S$ & 122.6 & $\mathrm{~m}^{2}$ \\
\cline { 2 - 4 } & Wing aspect ratio, $A$ & 9.395 & - \\
\cline { 2 - 4 } & Sweeper angle, $\chi$ & 25 & $\mathrm{deg}$ \\
\cline { 2 - 4 } Runway & Velocity of descent, $V$ & $82-116$ & $\mathrm{~m} / \mathrm{s}$ \\
\hline \multirow{3}{*}{ Engine } & Runway altitude, $h_{\text {runway }}$ & 498 & $\mathrm{~m}$ \\
\cline { 2 - 4 } & Altitude of descent, $h$ & 900 & $\mathrm{~m}$ \\
\cline { 2 - 4 } & Angle of descent, $\gamma$ & 3 & $\mathrm{deg}$ \\
\hline & Thrust, $T$ & 118 & $\mathrm{kN}$ \\
\cline { 2 - 4 } & $\begin{array}{l}\text { Thrust specific fuel } \\
\text { consumption, } t s f c\end{array}$ & 9.4444 & \multirow{2}{*}{$\mathrm{N} / \mathrm{sN}$} \\
\hline
\end{tabular}

\subsection{For modelling of jet engine jet noise}

The engine jet noise model requires specific input data with respect to geometry and operational conditions of the selected engine (Table 2). From the Airbus technical data are taken the geometric parameters [11]. The aircraft altitude, aircraft speed and the engine thrust setting determine the engine operation. According to the engine operation, specific engine thermodynamic parameters have to be generated.

To calculate the parameters of ambient condition it has been used the International Standard Atmosphere (ISA) [15]. The required specific design parameter of the engine for primary and secondary flow a turbofan calculator is used $[16,17]$.

Table 2. Engine noise modelling data.

\begin{tabular}{|c|l|c|c|}
\hline Data from & \multicolumn{1}{|c|}{ Parameter } & Value & Units \\
\hline \multirow{5}{*}{} & $\begin{array}{l}\text { Hydraulic diameter of } \\
\text { inner contour, } D_{19}\end{array}$ & 1.2 & $\mathrm{~m}$ \\
\cline { 2 - 4 } & $\begin{array}{l}\text { Hydraulic diameter of } \\
\text { outer contour, } D_{9}\end{array}$ & 1.8 & $\mathrm{~m}$ \\
\cline { 2 - 4 } & $\begin{array}{l}\text { Nozzle area of inner } \\
\text { Eontour, } A_{19}\end{array}$ & $\begin{array}{c}\text { Function of } \\
D_{19}\end{array}$ & $\mathrm{~m}^{2}$ \\
\cline { 2 - 4 } & $\begin{array}{l}\text { Nozzle area of outer } \\
\text { contour, } A_{9}\end{array}$ & $\begin{array}{c}\text { Function of } \\
D_{9}\end{array}$ & $\mathrm{~m}^{2}$ \\
\cline { 2 - 4 } & Polar angle, $\alpha^{*}$ & 45 & $\mathrm{deg}$ \\
\cline { 2 - 4 } & $\begin{array}{l}\text { Jet velocity in inner } \\
\text { contour, } v 9\end{array}$ & $219-593$ & $\mathrm{~m} / \mathrm{s}$ \\
\cline { 2 - 4 } & $\begin{array}{l}\text { Flow velocity in outer } \\
\text { contour, } v_{19}\end{array}$ & 230 & $\mathrm{~m} / \mathrm{s}$ \\
\cline { 2 - 4 } & $\begin{array}{l}\text { Jet temperature in inner } \\
\text { contour, } T_{9}\end{array}$ & $277-1132$ & $\mathrm{~K}$ \\
\cline { 2 - 4 } & $\begin{array}{l}\text { Flow temperature in } \\
\text { outer contour, } T_{19}\end{array}$ & 286 & $\mathrm{~K}$ \\
\hline \multirow{5}{*}{$\begin{array}{c}\text { Ambien } \\
\text { condition }\end{array}$} & Flow pressure, $p_{\infty}$ & 90811.7 & $\mathrm{~Pa}$ \\
\cline { 2 - 4 } & Flow temperature, $T_{\infty}$ & 282.206 & $\mathrm{~K}$ \\
\cline { 2 - 4 } & Flow density, $\rho_{\infty}$ & 1.121 & $\mathrm{~kg} / \mathrm{m}^{3}$ \\
\cline { 2 - 4 } & Sound speed, $c_{\infty}$ & 336.766 & $\mathrm{~m} / \mathrm{s}$ \\
\cline { 2 - 4 } & Mach number, $M$ & 0.219 & - \\
\hline
\end{tabular}

\section{Modelling of aircraft landing trajectory and jet engine noise}

The proposed model includes 2 sections.

\subsection{Modelling the aircraft landing trajectory}

Fig. 2 shows the aircraft model used in this study and the aircraft landing trajectory.

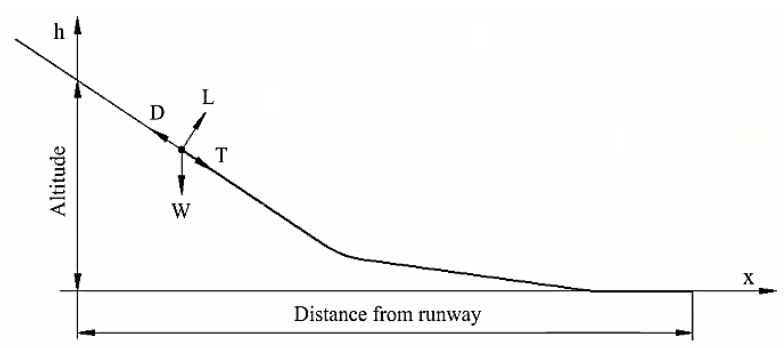

Fig. 2. Aircraft landing trajectory

For the differentials equations (1) describing the aircraft landing trajectory is valid the following fourdimension system derived at the aircraft centre of mass: 


$$
\begin{aligned}
& \dot{x}=V \cos \gamma ; \\
& \dot{h}=V \sin \gamma ; \\
& \dot{V}=\frac{T-D}{m}-g \sin \gamma ; \\
& \dot{m}=-t s f c T,
\end{aligned}
$$

where $(x, h)$ are the position of the aircraft, $(V, \gamma)$ are respectively the velocity and the angle of the descent. The variables ( $T$, $t s f c, D, m$ and $g$ ) are respectively the engine thrust, thrust specific fuel consummation, the drag force, the aircraft weight and gravity acceleration. Those variables are expressed as:

$$
\begin{aligned}
& T=T_{0} \delta_{x} \frac{\rho}{\rho_{0}}\left(1-M+\frac{M^{2}}{2}\right) ; \\
& D=\frac{1}{2} \rho S V^{2}\left(C_{x 0}+k_{i} C_{Z \alpha}^{2} \alpha^{2}\right) ; \\
& M=\frac{V}{c},
\end{aligned}
$$

with $T_{0}$ the full thrust, $\delta_{x}$ the throttle setting, $\rho$ the density of air at altitude, $\rho_{0}$ the density of air at ground, $M$ the Mach number, $S$ the wing span, $C_{Z \alpha}$ the gradient of the lift depends on the high lift device, $C_{x 0}$ the drag coefficient for $\alpha=0, k_{i}$ the induced drag coefficient, $\mathrm{c}$ the speed of sound at the altitude $h$ [18].

\subsection{Modelling of aircraft engine jet noise}

The jet noise consists of three principal components: turbulent mixing noise, broadband shock associated noise and screech tones. The jet noise is approximately omnidirectional during the descent phase and the noise levels decrease as speed decreases when assuming that the thrust is constant. It is extremely complex to predict the jet noise.

In this work to model the aircraft engine jet noise is used a semi-empire model of Stone [9]. The model assumes a symmetric noise emission with respect to the engine reference axis.

$$
L_{j e t}=L_{n o r m}+\Delta L_{\text {dir } / \text { spec }}\left(S t r_{c-j e} t, \alpha_{c o r}^{*}\right)+\Delta L_{c-j e t}
$$

$L_{n o r m}$ is a normalized sound pressure level and it is defined according to the nozzle geometry and the operating condition.

$$
\begin{aligned}
& L_{\text {norm }}=141.0+10 \log 10\left[\left(\frac{\rho_{\infty}}{\rho_{\infty, I S A}}\right)^{2}\left(\frac{c_{\infty}}{c_{\infty, I S A}}\right)^{2}\right]+ \\
& +10 \log 10\left(\frac{A_{9}}{d}\right)+10 \omega \log 10\left(\frac{\rho_{9}}{\rho_{\infty}}\right)+75 \log 10\left(\frac{\bar{v}_{9}}{c_{\infty}}\right)- \\
& -15 \log 10\left[\left(1+M \alpha_{c o n} \cos \left(\alpha^{*}\right)\right)^{2}+0.04 M \alpha_{c o n}^{2}\right]- \\
& -10 \log 10\left[1-M \alpha \cos \left(\alpha^{*}\right)\right]+3 \log 10\left(\frac{2 A_{9}}{\pi\left(D_{9}\right)^{2}}+0.5\right),
\end{aligned}
$$

where $\bar{v}_{9}$ is the effective jet speed defined as:

$$
\bar{v}_{9}=v_{9}\left[1-\frac{V}{v_{9}} \cos \left(\alpha^{*}\right)\right]^{\frac{2}{3}}
$$

$\omega$ is the exponent applies to hot jets:

$$
\omega=\frac{3.0\left(\bar{v}_{9} / c_{\infty}\right)^{3.5}}{0.6+\left(\bar{v}_{9} / c_{\infty}\right)^{3.5}}-1
$$

$M \alpha_{c o n}$ is a convective Mach number:

$$
M \alpha_{c o n}=0.62 \frac{v_{9}-V \cos \left(\alpha^{*}\right)}{c_{\infty}}
$$

$S_{t r 9}$ is an effective Strouhal number.

$$
\begin{aligned}
& \operatorname{Str}_{9}=f \frac{\sqrt{4 A_{9} / \pi}}{\bar{v}_{9}}\left(\frac{D_{9}}{\sqrt{4 A_{9} / \pi}}\right)^{0.4} \\
& \left(\frac{T_{t, 9}}{T_{t, \infty}}\right) 0.4\left[\left(1+\cos \left(\alpha^{*}\right)\right)\right]\left(1-M \alpha \cos \left(\alpha^{*}\right)\right) \\
& {\left[\frac{\left(1+0.62\left(\frac{v_{9}-v_{\infty}}{c_{\infty}}\right) \cos \left(\alpha^{*}\right)\right)^{2}+0.01538\left(\frac{v_{9}-v_{\infty}}{c_{\infty}}\right)^{2}}{\left(1+0.62\left(\frac{v_{9}}{c_{\infty}}\right) \cos \left(\alpha^{*}\right)\right)^{2}+0.01538\left(\frac{v_{9}}{c_{\infty}}\right)^{2}}\right]^{0.5}}
\end{aligned}
$$

with $\alpha^{*}$ cor is a corrected directivity angle defined as:

$$
\alpha_{c o r}^{*}=\alpha^{*}\left(v_{9} / c_{\infty}\right)^{0.1}
$$

$\Delta L_{c-j e t}$ is defined as:

$$
\begin{aligned}
& \Delta L_{c-j e t}= 5 \log 10\left(\frac{T_{t, 9}}{T_{t, 19}}\right)+ \\
&+10 \log 10\left[\left(1-\frac{v_{19}}{v_{9}}\right)^{m}+1.2\left(\frac{1+\left(\frac{A_{19}}{A_{9}} \frac{v_{19}^{2}}{v_{9}^{2}}\right)}{\left(1+\frac{A_{19}}{A_{9}}\right)^{3}}\right)\right]
\end{aligned}
$$

where the exponent $m$ is defined as a function of the area ratio:

$$
m=\left\{\begin{array}{lll}
1.1 \sqrt{A_{19} / A_{9}} \\
6.0
\end{array}\right\} \begin{array}{ll}
\text { for } & A_{19} / A_{9}<29.7 \\
\text { for } & A_{19} / A_{9}>29.7
\end{array}
$$

\section{Results and discussion}

An option which has to be evaluated in order to reduce the engine jet noise level in airports is the aircraft angle of descent.

In this work is considered an aircraft landing which model uses the following reference values [16] for: 
- angle of descent $\gamma=3^{\circ}$;

- velocity of descent $V=67 \mathrm{~m} / \mathrm{s}$;

- nominal weight $m=56000 \mathrm{~kg}$.

The landing duration is $140 \mathrm{~s}$. The throttle setting $\delta_{x}$ is constant during the landing. Graphics and numerical results are obtained from the proposed model. Fig. 3 shows the simulated aircraft landing trajectory for different angle of descent $\gamma$ which varies between $2.8^{\circ}$ and $3.4^{\circ}$ and different velocity of descent $V$ which varies between $53 \mathrm{~m} / \mathrm{s}$ and $67 \mathrm{~m} / \mathrm{s}$.

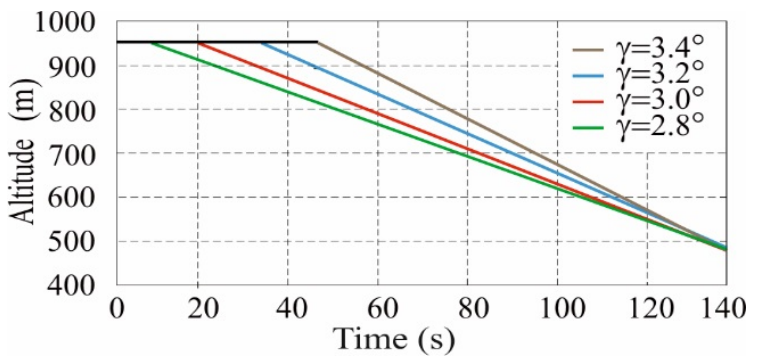

Fig. 3. Results from the simulated aircraft landing trajectory.

Table 3 shows the numerical values for calculated aircraft engine jet noise levels from the model for:

- different value of angle of descent $\gamma$;

- different velocity of descent $V$.

Table 3. Obtained numerical value from the jet engine model.

\begin{tabular}{|c|c|c|c|c|c|c|}
\hline Param. & \multicolumn{5}{|c|}{ Value } & Unit \\
\hline Angle & 3.0 & 2.8 & 3.2 & 3.4 & 3.0 & $\mathrm{deg}$ \\
\hline Weight & 56000 & 56000 & 56000 & 56000 & 64000 & $\mathrm{~kg}$ \\
\hline Speed & 67 & 74 & 60 & 53 & 67 & $\mathrm{~m} / \mathrm{s}$ \\
\hline Noise & 72.63 & 73.54 & 70.98 & 69.88 & 75.08 & $\mathrm{~dB}$ \\
\hline
\end{tabular}

As can be seen in table, according to the model:

- at a reference angle of descent $\gamma=3^{\circ}$ and a reference velocity of descent $V=67 \mathrm{~m} / \mathrm{s}$, the obtained level of aircraft jet engine noise is $72.630 \mathrm{~dB}$;

- at an angle of descent $\gamma=2.8^{\circ}$ and a velocity of descent $V=74 \mathrm{~m} / \mathrm{s}$, the noise level from the aircraft jet engine increases as compared to the reference angle by $0.92 \mathrm{~dB}$; - at an angle of descent $\gamma=3.2^{\circ}$ and a velocity of descent $V=60 \mathrm{~m} / \mathrm{s}$, the noise level from the aircraft jet engine decreases as compared to the reference angle by $1.65 \mathrm{~dB}$;

- at an angle of descent $\gamma=3.4^{\circ}$ and a velocity of descent $V=53 \mathrm{~m} / \mathrm{s}$, the noise level from aircraft jet engine aircraft decreases as compared to the reference angle by $2.75 \mathrm{~dB}$.

Obviously, the results show that there is a trend to reduce the aircraft jet noise after changing the angle of descent $\gamma$ and velocity of descent $V$. Larger variations in descent angle $\gamma$ and velocity of descent $V$ are limited by the difficulties of change in the landing procedure. When the aircraft landed, it spent much of its fuel and the weight of the passengers and baggage in the cargo compartment stays constant. Thus study with changing the aircraft weight $m$ is not necessary. However sometimes immediately after the aircraft takes-off, there is an emergency situation (incident) that causes an unplanned landing. In this cause the aircraft has a maximum landing weight. The model permits to calculate the noise level in this case also (Table 3 ).
Mathematical modelling is a modern research tool, but only when the proposed model is validated. To validate the calculated noise level of the aircraft jet engine it has been used experimental data from ten real flights (Table 4, Fig. 5) from Aircraft noise monitoring system at Munich airport (Fig. 4). The system operates currently with 16 stationary measuring stations which are positioned at a radius of some $20 \mathrm{~km}$ around the airport. Additionally three mobile measurement stations are also used at places where no stationary measuring station provides information about aircraft noise pollution [19].

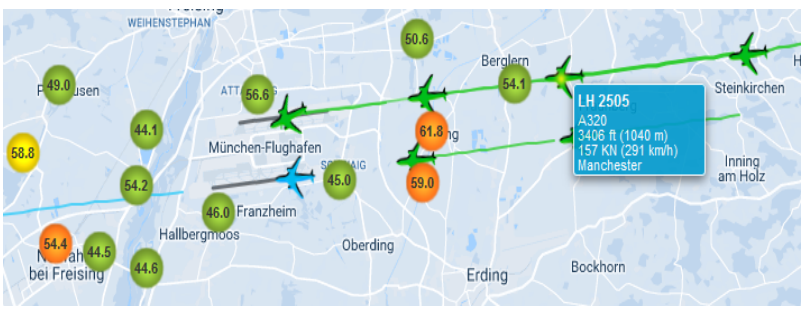

Fig. 4. Noise monitoring system at Munich airport.

Table 4: Data from the measurement station NMT7 at Munich airport runway $08 \mathrm{~L} / 26 \mathrm{R}$ on 30.04 .2018 and angle of descent $\gamma=3^{\circ}$.

\begin{tabular}{|c|c|c|c|c|c|c|}
\hline № & \multicolumn{2}{|c|}{ Flight } & Speed & Unit & Noise & Unit \\
\hline 1 & $\begin{array}{c}\text { Dublin- } \\
\text { Munich }\end{array}$ & EI 352 & 66 & $\mathrm{~m} / \mathrm{s}$ & 73 & $\mathrm{~dB}$ \\
\hline 2 & $\begin{array}{c}\text { Hanover- } \\
\text { Munich }\end{array}$ & $\begin{array}{c}\text { LH } \\
2093\end{array}$ & 69 & $\mathrm{~m} / \mathrm{s}$ & 72 & $\mathrm{~dB}$ \\
\hline 3 & $\begin{array}{c}\text { Berlin- } \\
\text { Munich }\end{array}$ & $\begin{array}{c}\text { LH } \\
2033\end{array}$ & 72 & $\mathrm{~m} / \mathrm{s}$ & 74 & $\mathrm{~dB}$ \\
\hline 4 & $\begin{array}{c}\text { Frankfurt- } \\
\text { Munich }\end{array}$ & LH 100 & 78 & $\mathrm{~m} / \mathrm{s}$ & 72 & $\mathrm{~dB}$ \\
\hline 5 & $\begin{array}{c}\text { Palma de } \\
\text { Majorca- } \\
\text { Munich }\end{array}$ & $\begin{array}{c}\text { DE } \\
1509\end{array}$ & 80 & $\mathrm{~m} / \mathrm{s}$ & 73 & $\mathrm{~dB}$ \\
\hline 6 & $\begin{array}{c}\text { Moscow- } \\
\text { Munich }\end{array}$ & $\begin{array}{c}\text { SU } \\
2322\end{array}$ & 70 & $\mathrm{~m} / \mathrm{s}$ & 71 & $\mathrm{~dB}$ \\
\hline 7 & $\begin{array}{c}\text { Berlin- } \\
\text { Munich }\end{array}$ & $\begin{array}{c}\mathrm{EZY} \\
5665\end{array}$ & 75 & $\mathrm{~m} / \mathrm{s}$ & 73 & $\mathrm{~dB}$ \\
\hline 8 & $\begin{array}{c}\text { London- } \\
\text { Munich }\end{array}$ & $\begin{array}{c}\text { LH } \\
2473\end{array}$ & 82 & $\mathrm{~m} / \mathrm{s}$ & 74 & $\mathrm{~dB}$ \\
\hline 9 & $\begin{array}{c}\text { Kiev- } \\
\text { Munich }\end{array}$ & $\begin{array}{c}\text { LH } \\
2545\end{array}$ & 77 & $\mathrm{~m} / \mathrm{s}$ & 73 & $\mathrm{~dB}$ \\
\hline 10 & $\begin{array}{c}\text { Berlin- } \\
\text { Munich }\end{array}$ & $\begin{array}{c}\text { LH } \\
2047\end{array}$ & 95 & $\mathrm{~m} / \mathrm{s}$ & 72 & $\mathrm{~dB}$ \\
\hline
\end{tabular}

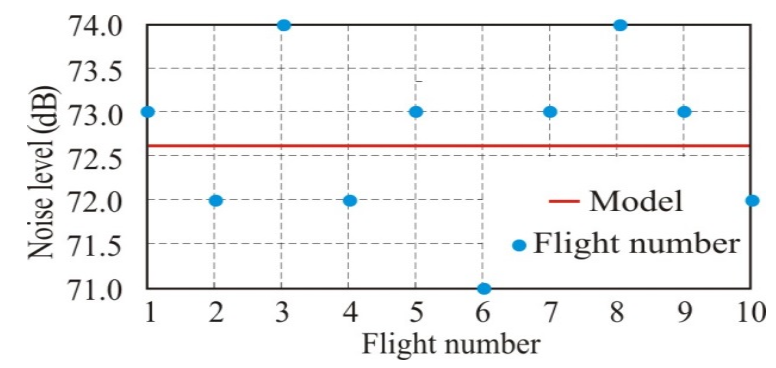

Fig. 5. Obtained results from the engine noise from the model and the real flight from the airport monitoring system.

The average deviation in the results from the jet engine model with the data from noise monitoring system is $1.1 \%$. 


\section{Conclusion}

A main source of noise from a low fly-over aircraft in the airports is its engine. In this work for simulating the aircraft landing trajectory is used: aircraft Airbus A320 widely used for short to medium range flights equipped with two CFM565A engines and runway of Munich airport which is one of the busiest airport in Europe.

The suggested model:

- is validated;

- shows graphical and numerical results;

- allows to study different possibilities of reducing the aircraft jet the noise level during landing in airports;

- allows to calculate the aircraft jet noise level in emergency situations;

- no complicated mathematical methods which reduces the calculation time;

- is general and gives the possibility to investigate the reduction of jet engine noise on aircraft equipped with engine without mixing flows.

In the future, the research will focus on creating a model to investigate the noise level of airframe and the engine model will be developed by adding the fan noise.

This work has been supported by Research and Scientific Centre of Technical University of Sofia (Grand № 181ПР0012-04).

\section{References}

1. http://www.futuresky.eu/projects/noise (30.07.2018)

2. EC, 2002, Directive 2002/49/EC of the European Parliament and of the Council of 25 June 2002 relating to the assessment and management of environmental noise, OJ L 129, 12-25 (18.7.2002)

3. E. Boeker, E. Dinges, B. He, G, Fleming, C. Roof, P. Gerbi, A. Rapoza, J. Hermann, Integrated noise model (INM) version 7.0 technical manual, FAA-AEE-08-01 (2008)

4. W. Krebs, Sound source data for aircraft noise simulation, Acta Acoustica united with Acustica, 90(1), 91-100 (2004)

5. S. Khardi, L. Abdallah, Optimization approaches of aircraft flight path reducing noise: Comparison of aircraft modelling methods, Applied Acoustics, 73, 291-301 (2012)

6. X. Menedez, Contributions to the optimisation of aircraft noise abatement procedures, Doctoral Thesis, Càtedra abertis de Gestión de Infraestructuras del Transporte Universitat Politècnica de Catalunya (2011)

7. F. Nahayo at al., Optimal control of two-commercial aircraft dynamic system during approach, The Noise Levels Minimization. Gen. Math. Notes, 3(2), 27-49, (2011)

8. R. Koenig, E. Schubert, On the influences of an increased ILS glide slope on noise impact, fuel consumption and landing approach operation, AIAC14 Fourteenth Australian International Aerospace Congress, 28 February - 3 March, Melburn (2014)
9. J. Stone, D. Groesbeck, C. Zola, Conventional profile coaxial jet noise prediction, AIAA Journal, 21(1), 336-342 (1983)

10. J. Bridges, A. Khavaran, C. Hunter, Assessment of current jet noise prediction capabilities, 14th Aeroacoustics Conference, Vancouver, Canada, May 5-7 (2008)

11. Airbus-AC-A320, Aircraft Characteristics - Airport And Maintenance Planning. AIRBUS S.A.S. Customer Services, Technical Data Support and Services, 31707 Blagnac Cedex, France (2016)

12. Airbus, Training\&Flight Operation support and services, Flight crew performance course, A318/A319/A320/A321, Performance Training Manual, 31707 Blagnac Cedex, France (2005)

13. http://ww1.jeppesen.com/personalsolutions/aviation/vfr-charts.jsp (30.07.2018)

14. https://www.aircraftnoisemodel.org/ (30.07.2018)

15. https://www.digitaldutch.com/atmoscalc/ (30.07.2018)

16. D. Adolfo, D. Bertini, A. Gamannossi, et C. Carcasci, Thermodynamic analysis of an aircraft engine to estimate performance and emissions at LTO cycle, $72^{\text {nd }}$ Conference of the Italian Thermal Machines Engineering Association, ATI2017, 6-8 September, Lecce, Italy (2017)

17. https://www.particleincell.com/2014/turbofancalculator/ (30.04.2018)

18. A. Bos, Aircraft performance summary tables for the base of aircraft data (BADA) revision 3.0. EEC Technical / Scientific Reports

19. https://travis-web01.munichairport.de/data/travis.php?lang $=$ en\&_ga $=2.41081378$. $185368683.1524577872-2134088401.1513440516$ (30.04.2018) 